\title{
Underwater technique for prevention of oil pollution
}

\author{
George Nerubenko \\ NER*MAR Limited, Toronto, Canada - National University of Shipbuilding, Nikolaev, Ukraine
}

Email address:

optimalproject@hotmail.com

\section{To cite this article:}

George Nerubenko. Underwater Technique for Prevention of Oil Pollution. Journal of Water Resources and Ocean Science. Special Issue: Safe Technology and Pollution Free Environment. Vol. 4, No. 1-1, 2015, pp. 1-10. doi: 10.11648/j.wros.s.2015040101.11

\begin{abstract}
The underwater tools, means, apparatus, vehicles and submarines are considered in the paper. It is stated that the majority of initial sources of petroleum pollution are underwater located. The novel concept of composing the emergency rescue complex is provided. The complex consists of best industrial technical components which could effectively solve the problem of underwater oil spillage caused by damaged oil tankers and offshore platforms.
\end{abstract}

Keywords: Emergency Rescue Operation, Offshore Oil Platform, Oil Spills, Submarine, Underwater Transportation

\section{Introduction}

The usage and exploitation of water resources brings the people to problem of providing pollution free environment. It could be achieved when exploiting technology is safe and specially designed meeting environment requirement. Some examples illustrate the necessity of such approach. Evaluation of sea polluting by damaged oil tankers had the following numbers: Exxon Valdez Tanker disaster (1989) was $\$ 6.0$ Billion, and Prestige Tanker was $\$ 4.0$ Billion in 2002. Sea polluting by damaged BP Deepwater Platform 2010 in Mexican Gulf was over \$ 42.0 Billion. The advanced technologies are presented and the ways of implementation into practice are shown. Marine sector is considered in this paper, specifically paying attention to oil spillage from tankers and from tank barges, and oil spills from offshore platforms. Only the sources of oil spills such as damages, holes, cracks, etc of tankers and oil platforms are targeting. While with transporting by tanker the Company is dealing with an object having a definite "oil spill size" knowing that the total amount of leaked oil will be limited (however the Company doesn't know where the spill might happen or what type of damage might be), with an offshore platform, the situation is the exact reverse. The location of incident is certain but the potential release quantity and duration are unknown. The selection of sources of oil spills as a theme of current paper has a simple explanation. It is cheaper, faster and much more effective to kill the problem in embryo source instead of creating several fences of defense: engineering, technological, biological, chemical, etc. The majority of oil spillage sources are located underwater. The scope of interest of this paper is the oil spills running from sinking damaged oil tankers and crushed elements of offshore platforms. Starting from 1985 the author was involved [1], [2] in design, R\&D of underwater tools, means, apparatuses, devices and submarines solving two problems: emergency rescue operations in marine petroleum industry and underwater transporting of oil and petroleum products.

\section{Examples of Underwater Petroleum Catastrophes}

The operation of technique in marine oil industry is accompanied by some natural malfunctions, accidents, wrecks, breakages, damages which occur from time to time. The amount and scope of damages could be different and should have random probability. But it is obvious that the bigger number of industrial objects would have the higher probability of non proper functioning, damages, breakages, and so on. Only for the Gulf of Mexico the approximate estimates indicate that there are 3600 production platforms, 300 drilling rigs, and 2500 vessels on a daily basis. EPA confirms that there are 20000 oil spills reported in the Gulf of Mexico yearly.

Unfortunately the huge disasters and catastrophes happen in marine oil industry. The Exxon Valdez oil spill [3], [4] occurred in Prince William Sound, Alaska, on March 24, 1989, when Exxon Valdez, an oil tanker struck Prince William Sound's Bligh Reef at 12:04 a.m. local time and spilled at least $41000 \mathrm{~m} 3$ of crude oil over the next few days, fouling about 2100 kilometers of coastline. The remote location of the spill and a delayed and inadequate response from Exxon and 
Trans-Alaska Pipeline operator ALYESKA made matters even worse. The oil slick had spread over 8000 square kilometers. The authors of [3] stated: "Exxon was not prepared for a spill of this magnitude- nor were Alyeska, the State of Alaska, or the federal government. It is clear that the planning for and response to the Exxon Valdez incident was unequal to the task. Contingency planning in the future needs to incorporate realistic worst-cast scenarios and to include adequate equipment and personnel to handle major spills."

On November 13, 2002, while the Greek-operated, single-hulled oil tanker Prestige [5] was carrying 77000 metric tons of cargo of heavy fuel oil, one of its twelve tanks burst during a storm in northwestern Spain. Thinking that the ship would sink, the captain called for help from Spanish rescue team, with the expectation that the vessel would be brought into harbor. However, pressure from local authorities forced the captain to steer the embattled ship away from the coast and head to French coast. Reportedly after pressure from the French government, the vessel was once again forced to change its course and head south into Portuguese waters. Fearing for its own shore, the Portuguese authorities promptly ordered its navy to prevent it from approaching further. The integrity of the oil tanker was quickly deteriorating, and during the storm it was reported that a 12 - meter section of the starboard hull had broken off, releasing a substantial amount of oil. At around 8:00 a.m. on November 19, the ship split in half. It sank the same afternoon, releasing over $76000 \mathrm{~m}^{3}$ of oil into the sea. After the sinking, the wreck continued leaking oil. It leaked approximately 125 tons of oil a day, polluting the seabed and contaminating the coastline. The affected area was a very prominent ecological region, supporting coral reefs and many species of sharks, birds and fishes. The heavy coastal pollution forced the local government to suspend offshore fishing for six months.

The BP Deepwater Horizon oil pollution disaster [6], [7] was caused by an explosion on the Deepwater Horizon offshore oil platform about 80 kilometers southeast of the Mississippi River delta on April 20, 2010. This resulted in 11 worker fatalities and a massive petroleum release. The Deepwater Horizon sank in about 1500 meters of water on April 22, 2010. After a series of failed efforts to plug the leak, BP said on July 15 that it had capped the well, stopping the flow of oil into the Gulf of Mexico for the first time in 86 days. Totally this subsea drilling system discharges petroleum of approximately $780000 \mathrm{~m} 3$ to U.S. waters. The oil slick produced by the Deepwater Horizon oil spill covered as much 75000 square kilometers. Such surface slick threatened the ecological systems and the economy of the entire Gulf Coast region. The underwater damages following by oil spills were the common characteristics of all these abovementioned catastrophes.

\section{Statistics of oil Spills}

There are several societies, institutions, organizations collecting the informational data about oil spills. It is very difficult to accumulate all statistical data in one body because of different nature of spills, different objects, different ways of recording and reporting, variety of areas, different tasks and addresses of reporting and so on. There are data of largest tanker spills collected in [8]. The data are based on reports of oil spills from one tanker and the volume of spilled oil from one tanker had to be over $37854 \mathrm{~m}^{3}$. Data were collected from 1960 to 1999 . Figure 1 shows the treated oil spill volume numbers (in $\mathrm{m}^{3}$ ) plotted for interval of years $1960-1996$. The reported data are presented by squared points interconnected with solid blue curved line. The trend-line approximation is plotted as solid red straight line. The graphical analysis indicates that the trend-line has the slight declining tendency. The absolute numbers of largest tanker spills are slightly reduced in $1960-1999$ period from $86000 \mathrm{~m}^{3}$ to $85000 \mathrm{~m}^{3}$.

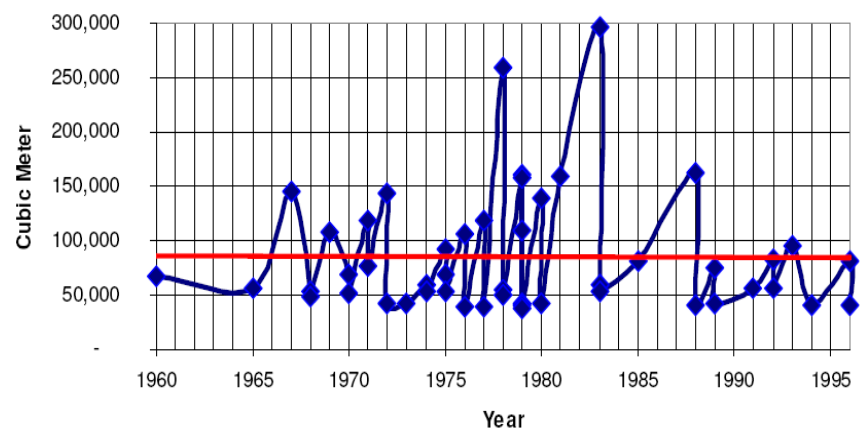

Figure 1. Largest tanker spills in 1960-1996. All spills of 37854 cubic meters or more.

ITOPF [9] gathered, maintained and analyzed a database of oil spills from tankers, combined carriers and barges. The collected information is about the accidental spillages since 1970 , except those resulting from acts of war and pirates.

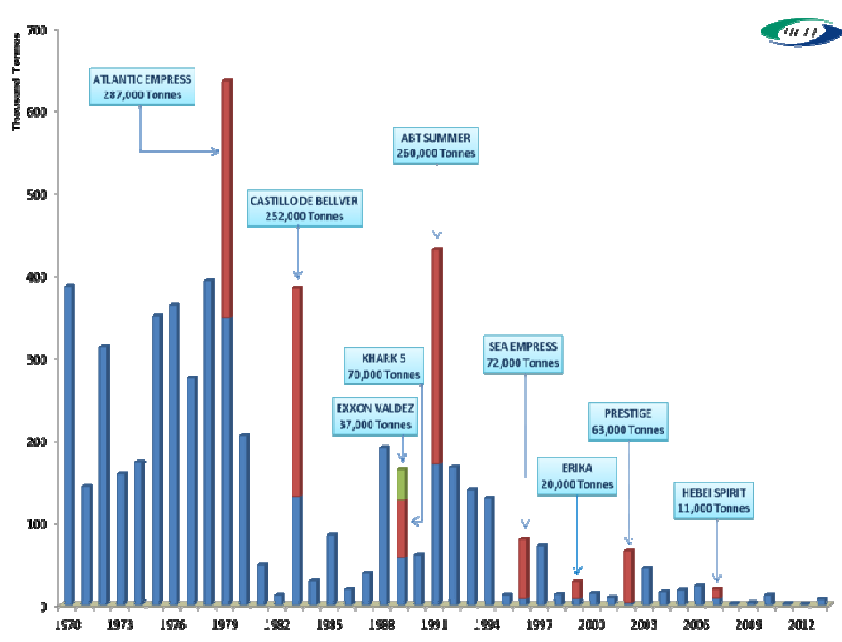

Figure 2. Quantities of oil spilt over 7 tones (rounded to nearest thousand), 1970 to 2013. (Copied from [9])

Quantities of tanker's oil spilt over 7 tones (rounded to nearest thousand), for time window 1970 - 2013 are shown in Figure 2[9]. In [9] it was underlined that usually a few very large spills were responsible for a high percentage of oil spilt. For instance, in four year period 2010-2013 there have been 28 spills of 7 tones and over, resulting in 22000 tones of 
petroleum lost. $90 \%$ of this volume was spilt in 8 incidents. Looking at the chart presented in Figure 2, it could be stated that it is clear evidence of sharp declining of tanker's oil spill tendency line starting from 2000.

It should be noted also that there has been a steady reduction in the number of offshore accidents reported by several studies. According to [10] (if to exclude the BP Deepwater well spill) in the average and median spill sizes, the size of spills from platforms tend to be smaller than those from tankers. For example, assuming that for 1964 -2013 interval the relative volume of oil spills from offshore platforms was $100 \%$, and for last 15 years this number was reduced to $29.5 \%$.Unfortunately the oil spill estimates are subjected by selected method of study (for example, see [11], [12]). There is no $100 \%$ proof that the situation with oil spills in the offshore platform industry is radically improved. As pointed out in [13], the most typical causes of accidents "include equipment failure, personnel mistakes, and extreme natural impacts (seismic activity, ice fields, hurricanes, and so on). Their main hazard is connected with the spills and blowouts of oil, gas, and numerous other chemical substances and compounds. The environmental consequences of accidental episodes are especially severe, sometimes dramatic, when they happen near the shore, in shallow waters, or in areas with slow water circulation. Broadly speaking, two major categories of drilling accidents should be distinguished. One of them covers catastrophic situations involving intense and prolonged hydrocarbon gushing. These occur when the pressure in the drilling zone is so high that usual technological methods of well muffling do not help. Drilling accidents are usually associated with unexpected blowouts of liquid and gaseous hydrocarbons from a well as a result of encountering zones with abnormally high pressure. No other situations but tanker oil spills can compete with drilling accidents in frequency and severity." Environmental impacts may arise at all stages of offshore platform activities, including initial exploration, production and final decommissioning. However the total amounts of underwater spills are very high and numbers of accidents are still significant.

One of the goals of petroleum engineers is a reduction of the environmental impacts of the petroleum industry on the marine environment, specifically through implementation of advanced underwater technique.

\section{Selection of Advanced Technology.}

There was the concept of universal marine transporting and emergency rescue salvage developed in 1980's [1] and [2].

The necessity of proposed concept was formulated during development of the underwater complex covering two tasks: emergency rescue combating the oil spills during salvage operation and underwater transportation of petroleum and its products during time period with no salvage operations. The ideas presented in [1] gave the opportunity propose the Marine Unit [2] of safe underwater transportation of oil and petroleum products combined with guaranteed prevention of oil spills. The concept is illustrated in Figure 3 schematically. The main schematic members of designed Salvage Unit are (see Figure 3) 1 - two rescue submarines, and 4 - salvage ship. Each of submarines is equipped by 2 - sucking pipe (hose) (for pumping out the oil from sunk damaged tanker or accepting the crude oil from underwater drill or damaged well 5), and 3 delivery pipe (hose) (for pumping in the collected oil to oil storage tank of ship 4). The ship 4 is equipped by EmergencyRescuer systems and devices as well.
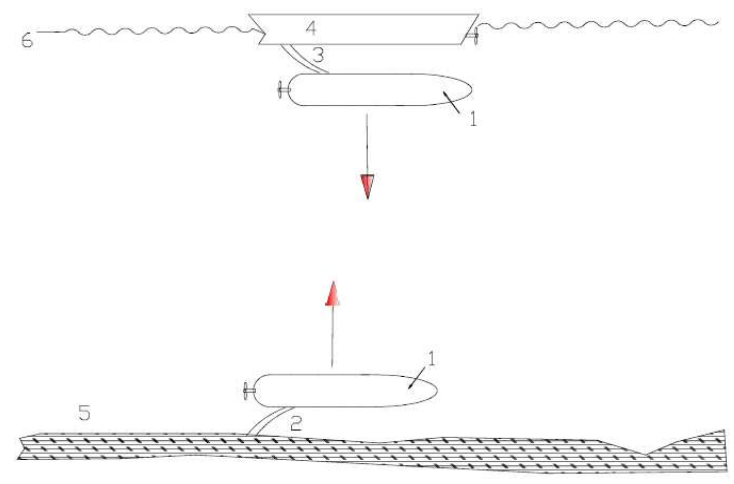

Figure 3. Proposed combined Salvage Unit.

The proposed configuration of Salvage Unit allows empty the damaged tanker (including the sinking tanker) in nonstop mode. One cycle of nonstop mode is as follows: while one submarine is involved in operation of discharging and pumping out the oil from damaged object, the other submarine is delivering the collected oil to ship's storage tank. The roles of submarines would be changed after finishing the cycle. When the emergency situation is over the submarines would be used as regular underwater tankers for transporting the petroleum products. Figure 3 shows the schematic skeleton of developed concept. It was proposed that submarines could have different shape configurations [1], [2], as shown in a Figure 4 as an example.
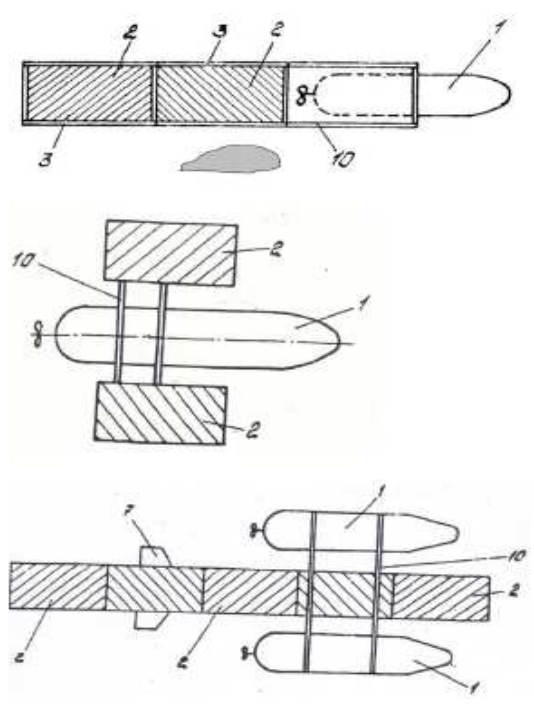

Figure 4. Versions of submarine equipped with additional tanks.

As per [1] the submarine 1 or underwater tugboat (see Figure 4) could carry several additional tanks 2 (or barges) 
allowing increase the volume of oil transport. Sometimes there are two submarines in one train (as presented in bottom part of Figure 4). Some tanks could have double-shelled 3 body structure. Tanks 2 and submarine 1 are interconnected by stiff framed self-adjusted carrier 10. Framed carrier 10 is affixed to tugboat 1 . The submarine 1 and framed carrier 10 are supplied by horizontal stabilizing rudders 7 for providing the maneuverability to whole train.

The bottom part of hose 2 (presented in Figure 3) should be connected to output flange of damaged sinking oil tanker, to specially installed temporary flange on the crashed part of tanker, or to properly organized point (usually also flanged) of damaged offshore platform. The submarine has the remote underwater robot (for instance, as shown in Figure 5 [14]) in its structure for these cases. The robot could have one or several manipulating arms for servicing the troubled object.

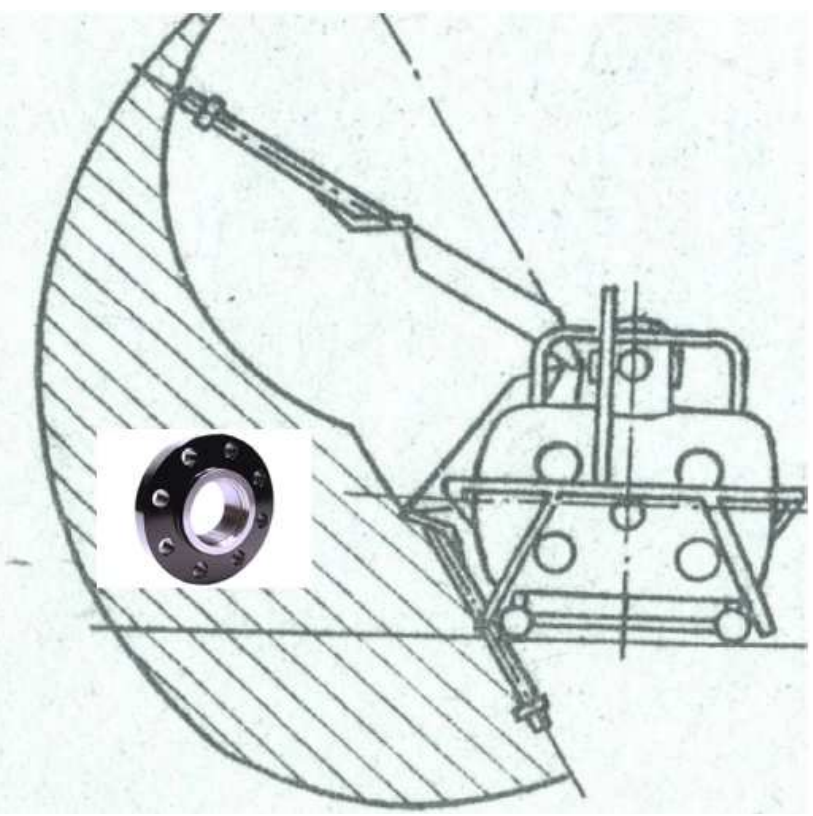

Figure 5. Underwater robot with manipulating arms.

The bottom part of submarine's hose 2 (shown in Figure 3) could be equipped by special connector - receiver as shown in Figure 6 [2]. This device is a remotely controlled self moving tuning apparatus. The main purpose of this device is providing the fast and spill free connection. The connector - receiver (see Figure 6) consists of 1 - the rigid strong housing, 2 protectors, 3 - fast acting connecting unit, 4 - a cap for connection to a flexible hose, 5 - a flexible hose, 6 - water-jets for maneuvering, 7 - the water-jet drives, 8 - TV cameras.

The presented in Figure 6 device has transfer capacity of $1000 \mathrm{~m} 3 / \mathrm{hr}$ of diesel fuel.

The Emergency - Rescuer ship 4(shown in Figure 3) contains the various types of systems and devices, however the main elements are [15] the Lifting Mechanism presented schematically as an example in Figure 7 in two positions, transit winch (see photo taken from [15] in Figure 8), and winch adjuster (see photo taken from [15] in Figure 9).
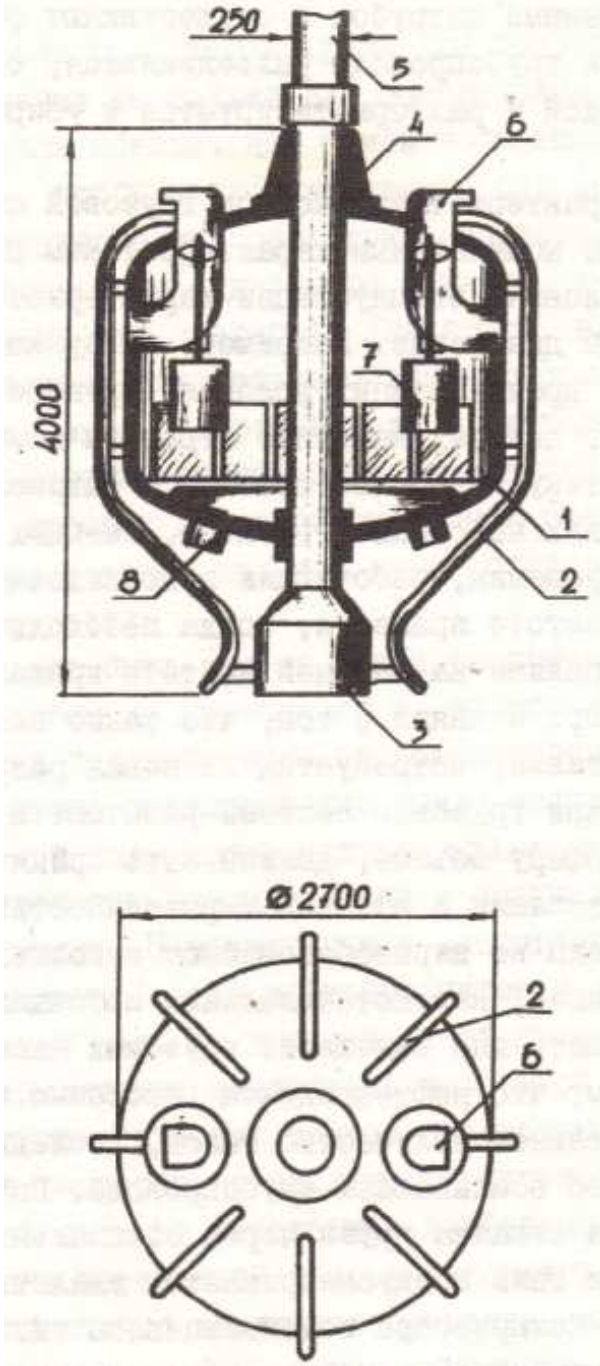

Figure 6. Underwater self propelling connector-acceptor.

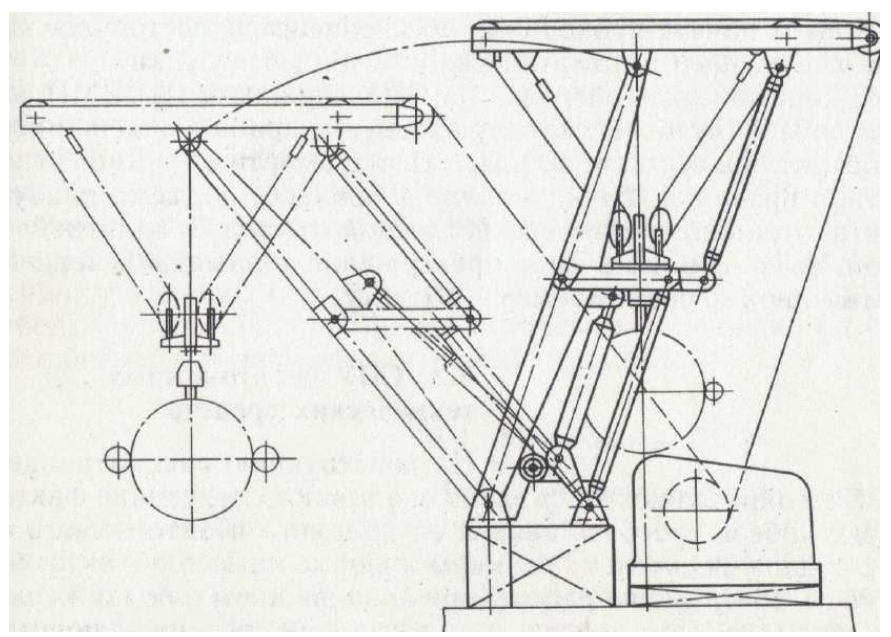

Figure 7. Lifting Mechanism. Max. Load 16 ton.

Professor David Tsagareli [2] had reported about project proving the idea and suggested method. The diesel propelled Russian navy submarine was converted into underwater rescuer. 


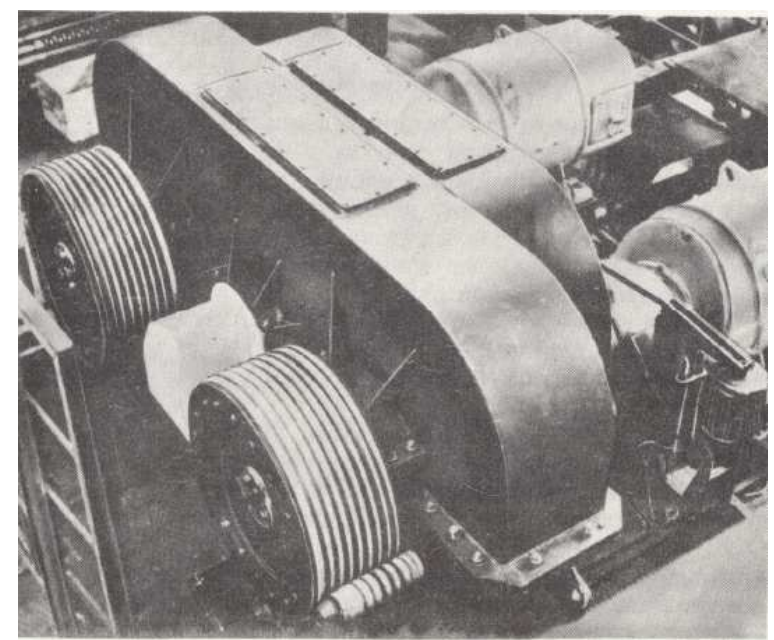

Figure 8. Transit winch $135 \mathrm{~kW}$. Drum Diameter $1000 \mathrm{~mm}$

This submarine had been equipped by special remotely controlled robot, and pumping system for sucking out the oil from sunk tankers (underwater position). The rescuer could accept around 9,000 MT of oil and oil products during one phase of pumping out operational session.

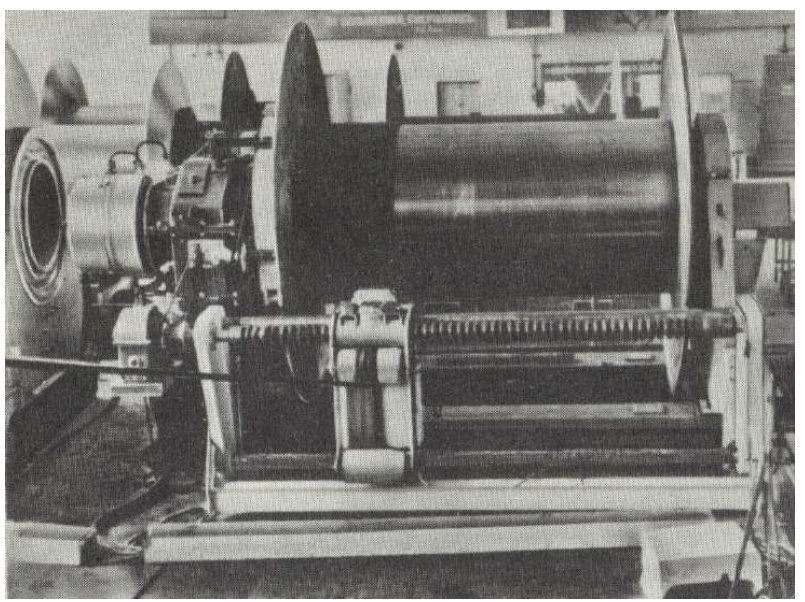

Figure 9. Winch adjuster $50 \mathrm{~kW}$. Drum Diameter $1200 \mathrm{~mm}$

There were two pumps in operation, and the one phase time was 8 hours. The timing of experiment was as follows: 1 hour - descending underwater and search for "damaged" tanker, 2 hours - robot operation, 1 hour - connection / disconnection, 8 hours - working phase, 1 hour - coming back to base, 8 hours pump out the tanker oil to base tanks. Actually one session took around 21-22 hours. "Sunken" tanker with 20,000 MT of crude oil was cleaned up in two days.

It is obvious that it should be the free time for the Salvage Unit when no accident happens. The exploitation of submarines could be planned as a transporting vehicle for this particular time interval. Figure 10 demonstrates the scheme of the underwater oil transportation applicable for Arctic regions covered by ice 26 [1]. The submarine - tanker 1 carries the oil tanks 2 interconnected by framed self adjusted carrier 10 . The tanks 2 are sitting on technological bed 14. For instance, the delivery station 11 includes the shore oil storage 12 and the shore ballast water storage 13 . The oil pipeline 15 is connecting the shore oil storage 12 to technological bed 14 . The ballast water pipeline 16 is connecting the shore ballast water storage 13 to technological bed 14 . The customer facility (for example receiving station 17) includes the shore oil storage 19 and the shore ballast water storage 18 similar to 13 and 12.

For increasing of the effectiveness of proposed concept and for providing the flexibility in operation some elements of system could be changed and improved. The content below would be dedicated to descriptions and presentation of the parts and components of discussed concept.

\section{Methods and Tools Solving the Underwater Oil Spill Problems}

In first phases of emergency rescue operation detailed observation of troubled site could be done using the equipment configuration presented in Figure 11 (taken from [16]). Herein the rescue ship 1 is connected to deep water garage 3 by means of wired cable 2 . The deep water garage 3 is connected to 5 - TV-controlled unmanned underwater apparatus by floating cable 4 . The considered complex allows executing the necessary jobs at depths down to $6000 \mathrm{~m}$ with consumed power of $30-60 \mathrm{~kW}$. The TV-controlled unmanned underwater apparatus could do a variety of operations and solve different tasks.

When the operation depth is to $500 \mathrm{~m}$, it is possible usage of other scheme - "a submarine connected to the unmanned apparatus by floating cable" as shown in Figure 12. In cases of dealing with narrow paths and constrained holes on depths to 600 meters the TV-controlled autonomous unmanned underwater apparatus could be used. The example of such apparatus is shown in Figure 13 (copied from [17]). This device could operate with loads up to $20 \mathrm{~kg}$.

A lot of attentions are dedicated to design of underwater apparatus and their components (see for example [14], [18], [19], [21]-[23], [26]). The German Lloyd has published rules for classification and construction [20] of unmanned submersibles (UUV); the operating and monitoring systems are also included in these rules. The rules [20] pointed out that unmanned submersibles may be Remotely Operated Vehicles (ROV) or Autonomous Underwater Vehicles (AUV). Well equipped an autonomous marine vehicle is proposed in [23]. The vehicle's configuration is including a rigid hull having an interior and a periphery, a deck joining the rigid hull at the periphery. Configured element is pivotally attached to the deck, and this element housing a plurality of sensors capable of effecting communication to and from the vehicle. In addition the vehicle could comprise various sensors and mission-specific hardware. Sensors include vehicle-mounted audio/video devices, radar, GPS and RF antennas, and other positioning and collision avoidance devices. Mission specific hardware includes various probes, protection systems, task and operational assemblies. 


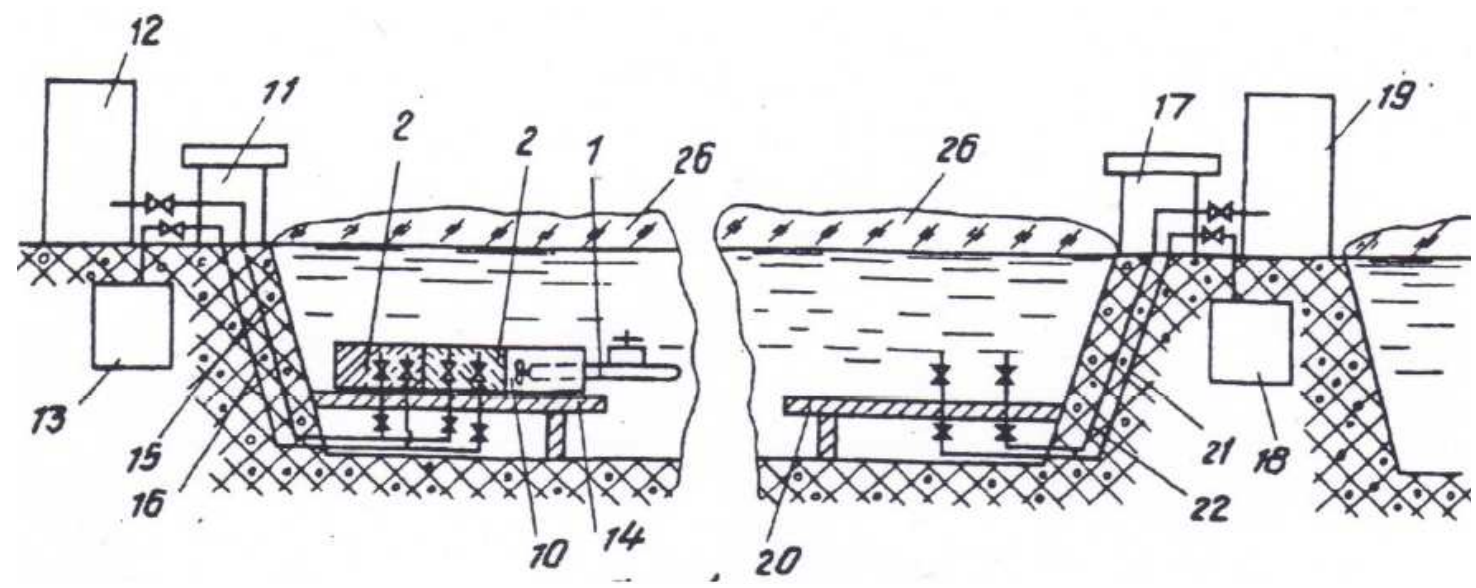

Figure 10. Technological scheme of underwater under-ice transportation.[1]

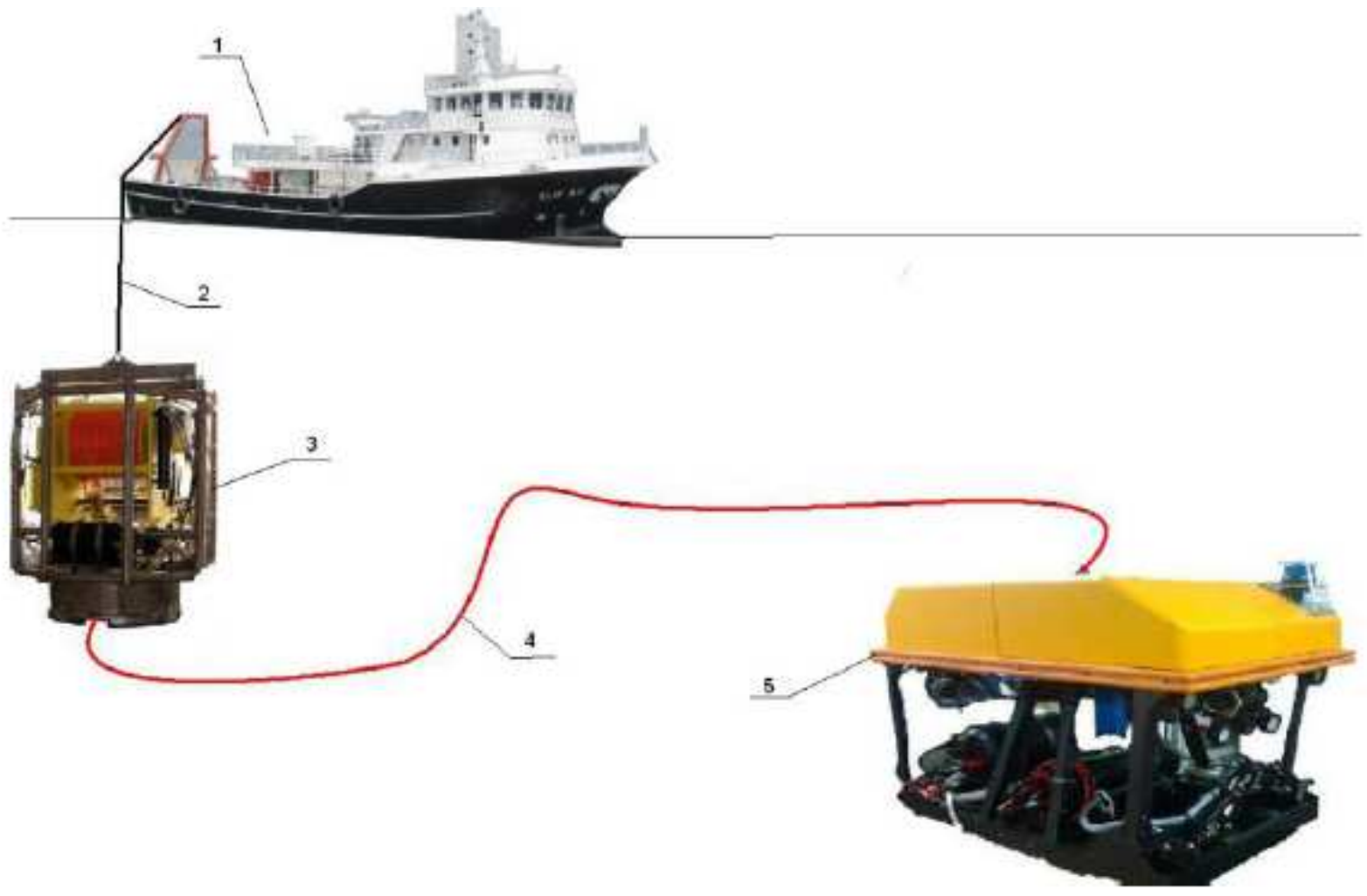

Figure 11. Scheme of underwater technical unit [16].

The laser-guided underwater robot is patented in [24]. The initial application of this robot was for reactor pressure vessel inspection, but underwater specifics could make its functionality and effectiveness much broader.

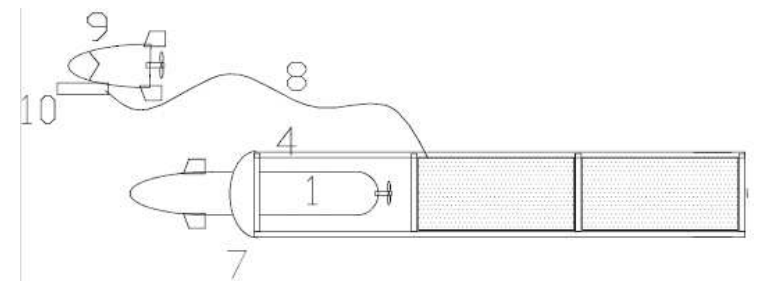

Figure 12. Underwater tanker with unmanned robot. 1-submarine, 4-framed carrier, 8-floating cable, 9-unmanned device, 10-Lights and TV camera.

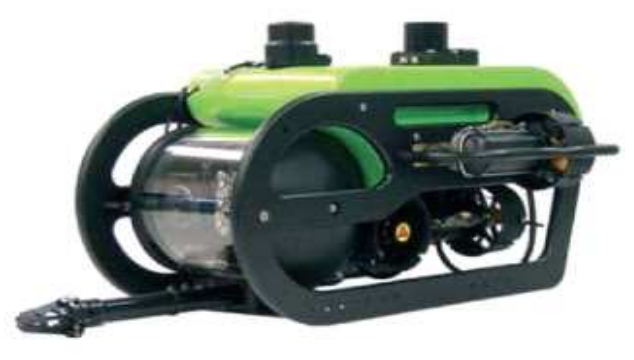

Figure 13. Underwater apparatus OBSOR 600 ([17])

An apparatus in [24] uses a laser driven type underwater robot guided by a laser pointer for the quick and adequate inspection of underwater object. The position control methods are provided for the stable guidance of the robot to desired 
three dimensional (3D) inspection positions on the various types of underwater objects.

The different tools arrangement for an autonomous unmanned underwater apparatus is presented in [25] (see Figure 14).

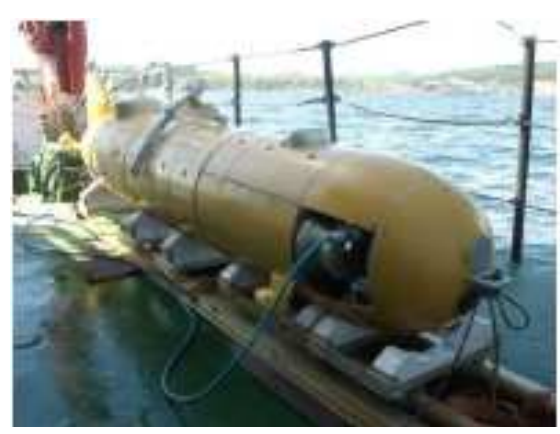

Figure 14. Underwater apparatus MMT 2012

Such apparatus could target the following tasks like search, observation and inspection of underwater objects on depths to 3000 meters, and provide a geological research as well.

All apparatus of above mentioned types and configurations would solve the problem of finding of underwater source of oil spillage, and (in some cases) handle the installation of flange for receiving line.

There are a lot of proved engineering solutions for cases similar to BP Deepwater well breakage. First of all it is necessary to cover the place of accident with a sort of cap or sarcophagus if such situations happen. The idea of that device was proposed in 1995 in [27] and presented in Figure 15.

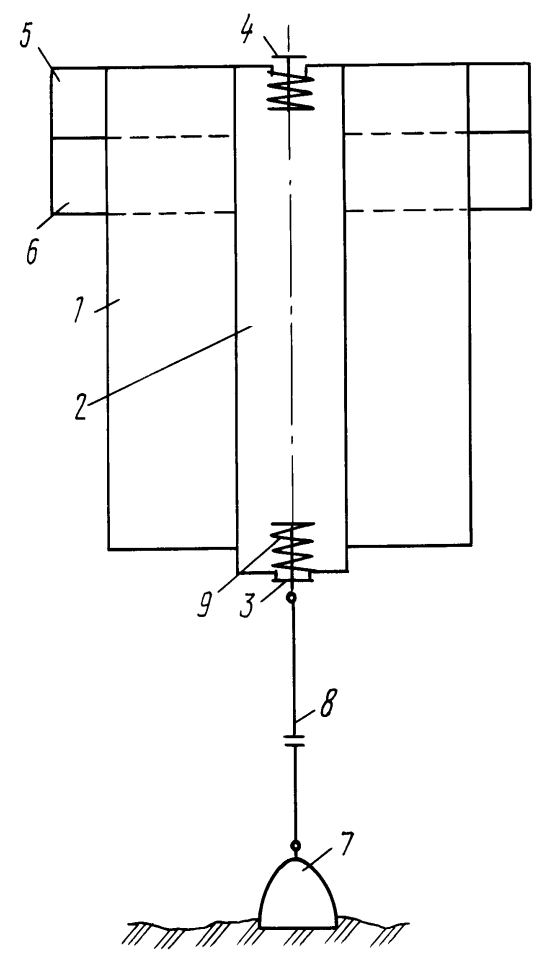

Figure 15. Device for subsurface oil gathering
Floating underwater vessel 1 (see Figure 15) is a ballast tank (unloaded hydrostatically from outer pressure). There is an equalizing tank 2 located in central part of 1 . The equalizing tank 2 contains valves 3 (fill up) and 4 (ventilation).There are tanks of permanent buoyancy 5 and of variable buoyancy 6 in the upper part of 1 . The special unit 7 is designed as an anchored collector covering the damaged well. The anchored collector is connected to valve 3 by pipe 8 . The forced drive 9 is inserted in valve 3 structure. Such devices could fulfill the coverage of crashed well and protect the environment from oil pollution. Another version of design is demonstrated in [28]. The analysis of designed and developed solutions provides the effective means for tackling the problems similar to BP Deepwater well disaster. Figure 16 illustrates the special coverage or sarcophagus which is solving two problems simultaneously- collection of oil running out from damaged unit and pumping the cement for sealing and capping the opening of hole. The presented selected device is a sort of combination of ideas developed in [2], [27] and [28]. Generally speaking the covering vessel is the sarcophagus mounted on ocean bottom by means anchors, keeping the sarcophagus inside volume from penetration of the outer water. There is a pipe on side upper part of the sarcophagus. This pipe is servicing the oil collecting mechanism (not shown in picture). There is a special pipe line mounted on top of the sarcophagus. That line is helping transport and pump-in the cement for capping purposes. It is necessary to note that the designs, drawings and related engineering packages and documents of such underwater sarcophagus were issued in 1995 and it would be the decision of industry to use them for oil pollution protection.

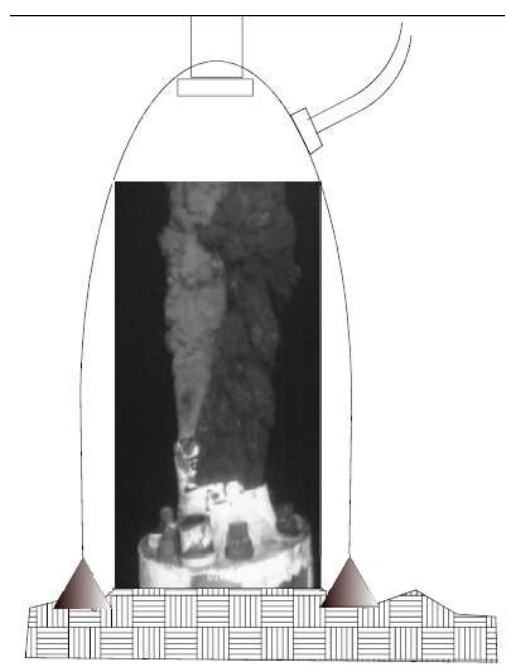

Figure 16. Underwater oil pollution protection device

The important component of proposed concept is the submarine which could work at depths 300-400 meters. Submarines would be the vessels converted from navy and adjusted as shown in Figure 4, or the multifunctional underwater tanker-rescuer could be built specifically for the discussed concept application. The information regarding two projects of these submarines was presented in [2]. The projects 
considered construction of underwater tankers with freight capacity of 9000 ton and 30000 ton. The schematic image of a tanker 9000 ton [2] is shown in Figure 17. The limited cargo capacity (9000 ton) was dictated by restriction of selected maximal submarine length of 170 meters. The designed underwater tanker consists of main master / navigator command cabin 1; rooms for living 2; engine room 3; pump room 4; cylindrical cargo tanks 5; main ballast tanks 6; ballast substitution tanks 7. The projected operational speed of a submarine was 14 knots, and the exploitation depth was 100 meters. The anticipated budget cost of construction was 19 million dollars. It had been supposed that the underwater tanker would be built within 45 months. Regarding the underwater tanker project of freight capacity 30000 ton the figures were as following: the length was 250 meters, the budget cost of building was 23 million dollars, and the predicted construction term was 50 months. These two projects demonstrated that the usage of underwater tankers would be the effective from financial point of view.

The attempt of creation of an unmanned autonomous automatic and self controlled submarine was provided in [29]. The proposed submarine would be programmed to dive to preset depths, move along preset trajectories, and return to the base. In addition to the autonomous properties, a remote control option is provided for the emergency situations or in order to perform special tasks.

The submarine is equipped with several sensors that can measure depth, orientation, attitude, location and speed. It is also equipped with an underwater video camera that can send wireless video pictures from underwater to the located above water surface monitor.

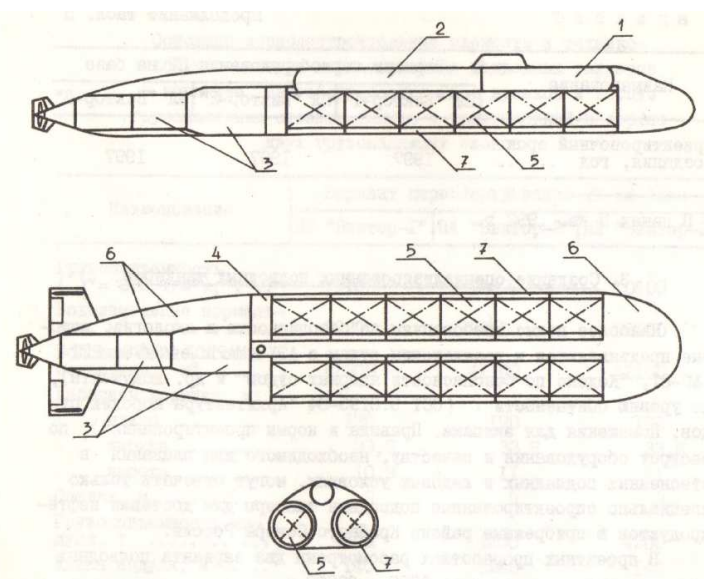

Figure 17. Underwater tanker. Cargo 9000 ton [2]

Various objectives of the unmanned autonomous submarine are to perform several tasks under water replacing crew, minimizing the cost of an underwater operations such as exploration, rescue, photography, and inspection of submerged structures (e.g. ship hulls, oil rigs, dams, etc.); monitoring various objects under water and transmitting live video and pictures to the operator on board of a commanding boat above water; being used as a carrier and base for underwater robotics, among other undersea functions and tasks. Figure 18 (taken from [29]) provides the some structural details of invented submarine in accordance to [29].

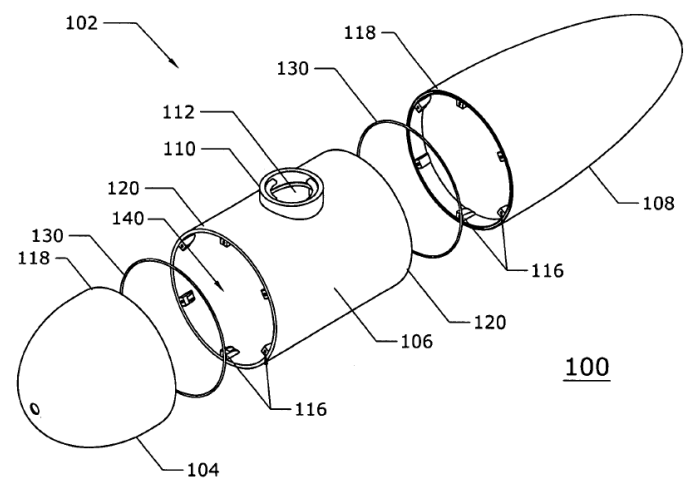

Figure 18. Submarine design in accordance to [29]

A submarine has several sections of hull 102: a forward hull section 104, a middle hull section 106, and an aft ward hull section 108. The submarine vessel can be assembled from two, three, or more hull sections with appropriate sealing devices 120. An opening 110 is formed in the upper side of one of the body sections, for instance the middle hull section 106, with a removable cover 112 . The opening 110 is provided for access to the cabin 140 during assembly and servicing of the submarine 100 . The removable cover 112 is provided to seal and protect the interior of cabin 140 of the submarine from the external water environment. Also additionally, the opening 110 facilitates assembly of the hull sections 108 using internal clamps 116. It is clear that the proposed submarine structurally based on approach which differs from one presented for submarine shown in Figure 17.

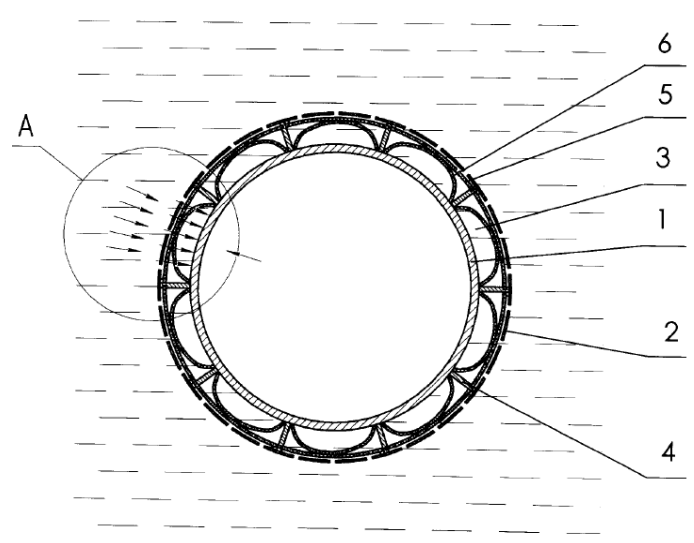

Figure 19. Freighter submarine, general section accordingly to [30]

The proper advanced protection of submarine metallic body with guaranteed zero leakage is suggested in [30]. Figure 19 (taken from [30]) shows the structural layout of the installation sheet lining of two layers of elastic material; Figure 20 shows the position of structural elements after sealing holes (when installing sheet lining of two layers of elastic material). The hull of the submarine cargo vessel contains a strong solid shell 1 , the outer casing 2, forming intermediate space 3 that communicates with the external 
environment. The intermediate space 3 is divided into definite sections by the structural elements 4 . The cover plate 5 (made of elastic material) is installed inside of intermediate space 3 . The cover plate 5 consists of two or more layers 6 of a specified material lay overlapping each other. One edge of the layer 6 is fixed on the structural elements 4 , and adjacent layers are fixed in opposite manner. The proposed idea works in a submerged position of a submarine as follows (see Figure 20). Let's assume that a hole as a result of accident has been formed in a solid prime shell 1 . The hole is initiating the pressure drop in the volume between the sheets 5 and prime shell 1. Under the influence of pressure drop the loose part of the layer 6 of the lining 5 is moved to the surface of the shell 1 , and in the same time moving along its surface. Thus, there is a displacement of bore in the plate 5 relatively to the hole in the solid shell 1. Finally the cover plate covers the hole in the solid shell 1 and the sealing of the holes would happen due to the elasticity of the material of the lining 5 . The proposed novel tool would reduce the time of water penetration into submarine.

It must be highlighted that the crew starts necessary rescue action immediately for the hull integrity restoration so the invented tool should help keep the submarine safety.

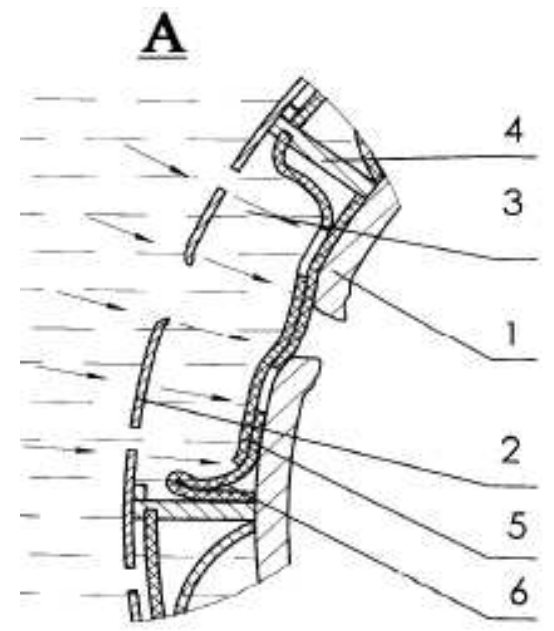

Figure 20. Freighter submarine, position of elements after sealing holes, accordingly to [30]

It is right time to say that an enormous amount of technical literature, research, development and engineering projects dealing with protection from underwater oil spills now exist, which has to be adequately organized and summarized. Of coarse, no one paper can include everything about the technique purposely struggling with underwater oil pollution. The emphases here are on effective and perspective engineering solution which is furnished in presented concept of the Three Component Salvage Unit.

A. For the oil tanker transporting industry it would be the first line of defence for oil spill prevention. The different situation is for offshore petroleum industry.

B. There is the proved concept of escape, evacuation and rescue measures developed and implemented in offshore petroleum industry (as an example, see [31], [32]), and the concept (like in [31], [32]) is the first line of defence. Hence, the proposed herein Three Component Salvage Unit concept would be the second line of defence for oil spill prevention for offshore petroleum industry.

\section{Conclusion}

The pollution caused by underwater oil spillage has a significant impact on the environment. The majority of underwater sources of oil spills are connected to oil tankers and offshore petroleum platforms. The presented concept of Three Component Salvage Unit could successfully solve the problem of underwater oil pollution. The main elements of proposed concept are: a. the emergency - rescuer ship fully equipped with various techniques, ready to fix the damages in oil tankers and offshore platforms, b. the submarines which could execute two tasks - rescue and oil transporting, c. supportive unmanned devices which may be remotely operated or autonomous underwater vehicles. The formulation of mostly effective means, tools and devices is developed from analysis of the best industrial samples. The designed composition of each component is based on the perspective novel engineering solutions. The presented concept provides the guaranteed reduction or avoidance of underwater oil pollution.

\section{Acknowledgements}

First of all the author pays a special tribute to Professor David Tsagareli (deceased) who initiated the creation of presented concept and delivered the tremendous effort into implementation and promotion of this project.

The author is very much thankful to Dr. F.G. Davletyarov who discovered new horizons and opportunities of the concept application.

Special thanks to Professor K.K. Glukharev who inhaled the life in this concept.

The author would like to thank Professor A. F. Gal and M. Eng. O.N. Abramov for the input of their design knowledge and engineering experience.

Finally the author wishes to pay a special tribute to departed Dr. S.S. Pavlov who had energized and led his team to implement in industry a majority of elements and devices of presented concept.

\section{References}

[1] A.F. Gal, K.K. Glukharev, G.P. Nerubenko, D.V. Tsagareli, O.N Abramov. Method of transporting of petroleum products and a device for its realization. Russian Patent 2037451. Oct 14, 1991

[2] V.P. Vinogradov, F.G. Davletyarov, K.K. Glukharev, A.V. Kuteynikiv, G.P. Nerubenko, V.V. Chernousov, D.V. Tsagareli. The underwater transportation of petroleum products to far north regions. Moscow, CNIITEN, 1993. 76 p.

[3] Samuel K. Skinner. William K. Reilly. The EXXON VALDEZ Oil Spill. A Report to the President. May 1989. The 
National Response Team

[4] Office of Exxon Valdez Oil Spill (EVOS) Damage Assessment and Restoration. http://alaskafisheries.noaa.gov/oil/

[5] Thomas Höfer. Tanker Safety and Coastal Environment: Prestige, Erika, and what else? ESPR - Environ Sci \& Pollut Res 10 (1) 1 - 5 (2003). Ecomed publishers, D-86899 Landsberg, Germany and Ft. Worth/TX, USA • Tokyo, Japan • Mumbai, India $\bullet$ Seoul, Korea.

[6] Curry L. Hagerty, Jonathan L. Ramseur. Deepwater Horizon Oil Spill: Selected Issues for Congress. Congressional Research Service. 7-5700. Report R41262. July 30, 2010. 48 p.

[7] Jonathan L. Ramseur, Curry L. Hagerty. Deepwater Horizon Oil Spill: Recent Activities and Ongoing Developments. Congressional Research Service. 7-5700. Report R42942. May 12 , 2014. $16 \mathrm{p}$.

[8] Oil Spill Intelligence Report. Southern Cross University, Australia. Aspen Publishers. 2000.

[9] ITOPF. Oil Tankers Spill Statistics 2013. London, United Kingdom, 2014.

[10] Cheryl McMahon Anderson, Melinda Mayes, and Robert LaBelle. Update of Occurrence Rates for Offshore Oil Spills. OCS Report BOEM 2012-069 BSEE 2012-069. June 2012, 76 pages.

[11] Kerr, Richard A. (13 August 2010). A Lot of Oil on the Loose, Not So Much to Be Found. Science 329. (5993): 734-5.Bibcode:2010Sci...329..734K. doi:10.1126/science.329.5993.734. PMID 20705818.

[12] Dagmar Schmidt Etkin. Analysis of oil spill trends in the United States and worldwide. Proceedings, 2001 International oil spill conference. pp. 1291-1300.

[13] Stanislav Patin. Environmental Impact of the Offshore Oil and Gas Industry. Ecomonitor Pub; 1 edition (December 1, 1999), $448 \mathrm{p}$.

[14] G.P. Nerubenko. Design of robot's drives. Textbook. Publisher: Shipbuilding Institute. Nikolaev.1985. 41 p.

[15] S.S. Pavlov, G.P. Nerubenko, B.N. Toropov. Advanced technology for modern ships. Shipbuilding SUDOSTROENIE. Leningrad.1988. $56 \mathrm{p}$.

[16] V.M. Rulevskiy, A.G. Yudintsev. The systems of electrical feeding of modern TV-controlled unmanned underwater apparatus. Proceedings of $5^{\text {th }}$ Conference "Technological Problems of Worldwide Ocean Development" Section 1. Vladivostok, Russia, 2013. pp. $108-112$.
[17] TETIS PRO. TV-controlled autonomous unmanned underwater apparatus OBSOR - 600. Catalogue, Moscow. 2014.

[18] Tadahiro Hyakudome. Design of Autonomous Underwater Vehicle. International Journal of Advanced Robotic Systems, Vol. 8, No. 1 (2011) ISSN 1729-8806, pp 131-139.

[19] Stokey, R. P. et al. (2005). "Development of the REMUS 600 autonomous underwater vehicle," OCEANS 2005. Proc. of MTS/IEEE, Vol.2 pp. 1301- 1304.

[20] Rules for Classification and Construction. I Ship Technology. 5 Underwater Technology. Germanischer Lloyd Aktiengesellschaft.. Hamburg 1 November 2009.

[21] Robert D. Goldbach. Apparatus and method for accommodating leaked oil within a double-hulled tanker after suffering grounding damage. US Patent 5520131. 1996

[22] Michael B. Geiger. Underwater self-propelled surface adhering robotically operated vehicle. US Patent 5947051, 1999.

[23] Richard Lawrence Ken Woodland. Autonomous marine vehicle. US Patent 6269763, 2001

[24] Jae-Hee Kim et al. Laser-guided underwater wall climbing robot for reactor pressure vessel inspection. US Patent 5809099 1998.

[25] L.A. Naumov, I.N. Borovik, A.I. Borovik. An autonomous unmanned underwater apparatus MMT-2012. Proceedings of $5^{\text {th }}$ Conference "Technological Problems of Worldwide Ocean Development" Section 1. Vladivostok Russia, 2013. pp. 46-48.

[26] Marine Robot Autonomy. Editor- Mae L. Seto. Department of Mechanical Engineering, Dalhousie University, Halifax. Springer New York 2013. 373 p.

[27] B.B. Klyachkin. Floating underwater vessel for collecting and storage of petroleum and petroleum products. Russian Patent. №:2021959. 1994.

[28] Eugene R. Barnett, Deep sea oil salvage means. US Patent $4,531,860.1985$

[29] Khaled R. Asfar et al. Unmanned autonomous submarine. US Patent 7290496. 2007.

[30] V.B. Shepelenko. Freighter submarine. Russian Patent RU 2488516. 2013

[31] Canadian Association of Petroleum Producers. Spill prevention and response in Atlantic Canada. Brochure. 2006-0012, 2006. 4 pages.

[32] Atlantic Canada Offshore Petroleum Industry Escape, Evacuation and Rescue. Guide. Canadian Association of Petroleum Producers (CAPP). June 2010. 2010-0017. 34 pages. 